\title{
Erratum to: What is the best moment to apply phototherapy when associated to a strength training program? A randomized, double-blinded, placebo-controlled trial
}

\author{
Adriane Aver Vanin ${ }^{1,2} \cdot$ Eduardo Foschini Miranda ${ }^{1,3}$. \\ Caroline Santos Monteiro Machado ${ }^{1}$ Paulo Roberto Vicente de Paiva ${ }^{1,3}$. \\ Gianna Móes Albuquerque-Pontes ${ }^{1,3}$ • Heliodora Leão Casalechi ${ }^{1}$. \\ Paulo de Tarso Camillo de Carvalho ${ }^{1,2,3}$ - Ernesto Cesar Pinto Leal-Junior ${ }^{1,2,3,4}$
}

Published online: 6 December 2016

(C) Springer-Verlag London 2016

Erratum to: Lasers Med Sci (2016) 31:1555-1564

DOI 10.1007/s10103-016-2015-7

The published online version is missing protocol number in "Material and Methods" part. The sentence should read as follows:

The project received approval from the institutional research ethics committee (protocol number 437.894). The study protocol was registered under the number NTC02474602 in NIH Clinical Trials.

The online version of the original article can be found at doi:10.1007/s10103016-2015-7.

Ernesto Cesar Pinto Leal-Junior ernesto.leal.junior@gmail.com

1 Laboratory of Phototherapy in Sports and Exercise, Universidade Nove de Julho (UNINOVE), São Paulo, SP, Brazil

2 Postgraduate Program in Rehabilitation Sciences, Universidade Nove de Julho (UNINOVE), São Paulo, Brazil

3 Postgraduate Program in Biophotonics Applied to Health Sciences, Universidade Nove de Julho (UNINOVE), São Paulo, Brazil

4 Laboratory of Phototherapy in Sports and Exercise, Rua Vergueiro 235/249, CEP: 01504-001 São Paulo, SP, Brazil 